\title{
STAVOVI POLJOPRIVREDNIH STRUČNJAKA PREMA ANGLICIZMIMA/PREVODNIM EKVIVALENTIMA U NAUČNOJ TERMINOLOGIJI NA SRPSKOM JEZIKU
}

Sve veća upotreba anglicizama u srpskom naučnom diskursu vodi ka potrebi za usaglašavanjem naučne terminologije na srpskom jeziku. Iako se smatra da je u naučnim i stručnim oblastima sve precizno i jasno, kada je u pitanju terminologija, situacija je daleko od idealne. Imajući u vidu anglicizme i njihove prevodne ekvivalente, stiče se utisak da stručnjaci koriste termine onako kako njima najviše odgovara. Tako, nailazimo na primere termina, direktno preuzetih iz engleskog jezika bez ikakvog prilagođavanja srpskom jeziku, prevedenih ili poluprevedenih na srpski jezik, koji, pri tom, označavaju isti pojam. S tim u vezi, u ovom radu smo naveli moguće načine vrednovanja terminoloških alternativa oslanjajući se na već postojeće modele. Cilj rada jeste da se ispitaju stavovi poljoprivrednih stručnjaka u vezi sa upotrebom anglicizama, odnosno srpskih prevodnih ekvivalenata u naučnoj terminologiji na sprskom jeziku. Istraživanje je sprovedeno među stručnjacima iz različitih oblasti poljoprivrede. Rezultati ukazuju na postojanje proizvoljnosti prilikom korišćenja terminoloških alternativa, kao i na neophodnost sveobuhvatnijeg istraživanja i timskog rada lingvista i stručnjaka iz određenih naučnih oblasti, kao i podrške relevantnih državnih institucija kako bi se postojeći termini uskladili i time smanjila nedoslednost, nepreciznost i nejasnost u naučnoj terminologiji.

Ključne reči: engleski jezik, srpski jezik, naučna terminologija, poljoprivreda.

\section{Uvod}

Danas se sve više govori o globalizaciji i njenom uticaju ne samo na ekonomskom, već i političkom i kulturnom planu. Svet se integriše, komunikacija je olakšana, te se stvara utisak da svet više nije podeljen na države, već da predstavlja jednu veliku zajednicu.

* Nemanjina 6, 11080, Beograd-Zemun, ddj@agrif.bg.ac.rs 
Kao sredstvo komunikacije već duže vreme se koristi engleski jezik koji ima potpuni primat u skoro svim delovima sveta. Takođe, kao lingua franca, engleski jezik je uspeo da se uvuče u sve oblasti ljudskog delovanja: modu, ishranu, nauku, tehnologiju, poljoprivredu, turizam, da spomenemo samo tek neke.

Razne institucije kojima „manji” narodi žele da zaštite svoj jezik i ostale oblasti ljudskog delovanja se javljaju kao odgovor na globalizaciju i sve veći uticaj engleskog jezika. U Srbiji postoji nekoliko institucija čiji je posao između ostalih i rad na standardizaciji srpskog jezika. Međutim, njihov učinak nije na zavidnom nivou, te se stiče utisak nedorečenosti i nezainteresovanosti, što je možda rezultat nepostojanja odgovarajućih ovlašćenja, kadrova i sredstava. Prćić (2006a) čak govori o postojanju anglosrpskog jezika i ,angloCOOLturi”. Primer haotičnosti i nesklada se može naći i u naučnoj terminologiji, gde svako kroji reč prema svom nahođenju.

U radu ćemo navesti polidimenzioni pristup vrednovanja terminoloških alternativa u procesu izgrađivanja terminologije iz bilo koje oblasti (Bugarski, 1996b). Pristup na koji ćemo se osloniti u istraživanju terminoloških alternativa iz oblasti poljoprivrede jeste poludimenzioni pristup koji su koristili Filipović i Filipović (1997) u svom istraživanju o terminološkim alternativama iz nekoliko oblasti.

Cilj ovog rada jeste da se na malom uzorku ispitaju stavovi poljoprivrednih stručnjaka prema upotrebi anglizicama, odnosno srpskih prevodnih ekvivalenata u naučnim radovima.

\section{Globalizacija i engleski jezik kao globalna lingua franca}

Usled sve veće globalizacije i povezivanja ljudi, engleski jezik je postao lingua franca ,koji se može definisati kao jezik koji se koristi kao sredstvo komunikacije među pripadnicima različitih lingvokulturnih grupacija kojima dati jezik nije L1" (Filipović, 2009: 97).

Meyerhoff (2006: 245) globalizaciju definiše kao skorašnji fenomen koji je povezan sa novijim tehnologijama komunikacije. Danas se život gotovo ne može zamisliti bez interneta i mobilnog telefona, ili kako se često navodi: „Ono što nije zapisano na fejsbuku se zapravo nije ni dogodilo”. O globalnom širenju engleskog jezika u dvadesetom veku, a posebno tokom 
STAVOVI POLJOPRIVREDNIH STRUČNJAKA PREMA ANGLICIZMIMA/PREVODNIM EKVIVALENTIMA U NAUČNOJ TERMINOLOGIJI NA SRPSKOM JEZIKU

njegove druge polovine, posle Drugog svetskog rata govori i Ostler (2008: 591-592), koji ukazuje na ogroman uticaj Sjedinjenih Američkih Država.

\section{Uticaj engleskog na srpski jezik}

I sami smo svedoci sve veće upotrebe engleskog jezika koji se ne ogleda samo u upotrebi u govornom srpskom jeziku, već i na drugim poljima čovekovog delovanja. Hlebec smatra da se uvođenjem anglicizama rečnik bogati pojmovno ukoliko ranije nije postojao odgovarajući naziv, kao i kada treba ukazati na male ali važne razlike, dajući primer da stranci kod nas više vole pljeskavice od hamburgera. Takođe, smatra da pozajmice obično pružaju i veće mogućnosti za građenje novih reči. Međutim, ističe da ne treba preterivati i dalje navodi da ,se, bez preke potrebe, umesto kontrolni punkt pojavilo čekpoint, džekpot umesto premija, hepiend je zamenilo srećan kraj, kasting audiciju, a tender konkurs" (Bojković, 2010, italik autorov).

O uticaju engleskog na srpski jezik kao i o neophodnosti standardizacije i mogućim rešenjima u različitim oblastima su pisale Mićić i Sinadinović (2013), Mirić (2013), Silaški (2012) i dr.

Dakle, pitanje koje se nameće jeste: postoji li neko pravilo u kojim situacijama (ne)koristiti anglicizme? Reklo bi se da je odgovor lak, jer postoji standardizacija jezika, naročito ako govorimo o naučnoj terminologiji, gde se smatra da sve mora biti jasno i prezicno definisano. Međutim, da li je tako?

\section{Standardizacija srpskog jezika}

U svom radu ,Srpski ili anglosrpski - pitanje je sad” Prćić (2006b: 419) ukazuje na jezičku anglomaniju kao jedinstveni jezički, sociološki i kulturološki fenomen. On navodi da je neophodna razrađena standardološka strategija, kontaktna jezička kultura, vezana za kontakte između srpskog i stranih jezika, prvenstveno srpskog i engleskog jezika, koja bi omogućila doslednu upotrebu reči iz stranih jezika. Zaključuje se da odgovor na postavljeno pitanje u naslovu navedenog rada nedvosmisleno mora glasiti: ,isključivo srpski, ali u koji su uključene opravdane i potrebne pozajmljenice iz engleskog jezika, koje se valjano pišu, izgovaraju i menjaju po padežima ili licima" (Prćić, 2006b: 420). 
Međutim, već duže vreme pokušaji standardizovanja srpskog jezika, pogotovo naučne terminologije su bezuspešni, te jedino što preostaje, kako se čini, jeste da se piše o tome. Ističe se da su se dosadašnja standardizacija i jezička politika u Srbiji bavile pitanjima i problemima odnosa statusa, jezičkog korpusa i sociolingvističkih konotacija srpskog jezika u odnosu na srpskohrvatski, hrvatski, bošnjački ili bosanski i crnogorski, gde se jezik sagledava kao osnovni nosilac ,narodnog, kulturnog, standardnojezičkog, političkog i sveukupnog državnog jedinstva" (Brborić, 2006b u Filipović, 2009: 63), sa jedne strane, odnosno, problemima ugroženosti opstanka čistote i integriteta pred prodorom uticaja engleskog jezika, sa druge strane (Filipović, 2009: 63).

Imajući navedeno u vidu može se zaključiti da zasada u Srbiji postoji nekoliko struja u vezi sa (ne)upotrebom anglicizama, odnosno srpskih prevodnih ekvivalenata: dve ekstremne i jedna umerena. Od ekstremnih se, s jedne strane, izdvajaju oni koji su za potpunu internacionalizaciju, tj. za što češće korišćenje stranih reči i izraza, i s druge strane, oni koji su suprotnih shvatanja i koji bi da sve odomaće ne vodeći računa da li se u prevodu gubi nešto od značenja datih reči i izraza. Treću struju čine oni koji, kako izgleda, nisu sigurni šta je ispravno, jer pravila zapravo nema, pa smatraju da je ipak najbolje biti neopredeljen i naći se negde u sredini.

\section{Standardizacija naučne terminologije u srpskom jeziku}

Bugarski (1996a: 75) ističe da je reč terminologija izrazito višeznačna, te da ima bar pet značenja od kojih je za ovaj rad najznačajnije prvo: skup termina koji reprezentuju sistem pojmova neke oblasti. Smatra se da je za dobru standardizaciju naučne terminologije potreban udružen i timski rad s jedne strane stručnjaka - terminologa, i sa druge strane - lingvista (Stojanović, 1996: 115). S tim u vezi, Vinaver (1996:23) ističe da iza uspešne standardizacije stoji ,jасна државна политика према свим економским интересима, према националној индустрији, целокупној производњи, истраживачким установама, свим услугама и да се посебно истиче језичка политика" te da negovanje terminologije pored informacione uloge spada i u jezičko planiranje. Ovo je od velike važnosti s obzirom na činjenicu da smo mi zemlja „чија је технологија веома зависна од иностраног искуства и његовог адекватног превођења" (Vinaver, 1996:23). O potrebi za usklađivanjem terminologije pisali su i Molnar 
STAVOVI POLJOPRIVREDNIH STRUČNJAKA PREMA ANGLICIZMIMA/PREVODNIM EKVIVALENTIMA U NAUČNOJ TERMINOLOGIJI NA SRPSKOM JEZIKU

i sar. (1999) ukazujući na moguća pogrešna tumačenja pojmova usled neusklađenosti termina. Silaški (2012: 123) ističe, doduše u vezi sa terminologijom iz oblasti marketinga i menadžmenta, da se novi termini iz engleskog jezika uvode neplanski, na osnovu ličnih želja i nahođenja ekonomista i prevodilaca. Čini se da to nije slučaj samo sa navedenim oblastima, već i sa većinom drugih naučnih oblasti u kojima se oseća uticaj engleskog jezika.

Zadatak oko usklađivanja naučne i stručne terminologije je nesumnjivo težak, ali se verovatno donekle može rešiti. Pitanje je samo koliko su stručnjaci iz odgovarajućih oblasti zainteresovani i motivisani da se bave navedenim problemom. Čekanje neće popraviti stvari, niti izmeniti činjenicu da je u srpskom jeziku neophodna standardizacija naučne terminologije i da to nije stvar pojedinca, već grupe stručnjaka iz različitih oblasti, kao i odgovarajućih državnih institucija koji bi trebalo da ozbiljno pristupe problemu i da ga na dosledan način reše.

\section{Polidimenzioni pristup (Bugarski, 1996b)}

Imajući u vidu proces izgrađivanja, sistematizovanja i prihvatanja lingvističkih termina, i naučnih termina uopšte, Bugarski (1996a: 92) navodi četiri grupe kriterijuma: formalne, semantičke, pragmatičke i sociolingvističke. Takođe, pažnja se skreće i na činjenicu da naučna terminologija mora da teži spoljnoj integraciji - drugim rečima, da bude u velikoj meri internacionalna, kako bi bila funkcionalna za sve potrebe (Bugarski, 1996a: 95).

Naravno, sve ovo je ,samo jedan deo složenih poslova koje podrazumevaju napori usmerene ka izgrađivanju, konsolidovanju i širenju takve terminologije koja bi jednovremeno bila lingvistički valjana, sociolingvistički prihvatljiva, i primerena potrebama kako naučnog i stručnog razvoja tako i nacionalne, međunacionalne i internacionalne komunikacije" (Bugarski, 1996a: 100). Odavde proizilazi da se ne može beskrajno insistirati na čistoti jezika i njegovom kaljanju upotrebom stranih reči, prvenstveno anglicizama, već se mora voditi računa i o internacionalizaciji termina, koja predstavlja bitnu stavku prilikom stvaranja naučne terminologije.

Bugarski (1996b: 25) predlaže polidimenzioni pristup vrednovanja terminoloških alternativa u procesu izgrađivanja terminologije bilo koje 
oblasti. Opisuje eksperimentalnu matricu sa deset odabranih raznorodnih kriterijuma (sistemnost, produktivnost, jednoznačnost, internacionalnost, motivisanost, raširenost, stabilnost, konotacije, kratkoća i lakoća) kroz koju propušta pet terminoloških alternativa našeg jezika (kompjuter/ računar, printer/štampač, fidbek/povratna sprega, menadžment/poslovanje, interakcija/međudejstvo). Takođe se ukazuje na mogućnost hijerarhije kriterijuma i kvantifikacije prednosti jednog člana ovakvih parova (Bugarski, 1996b: 25). Ukoliko ispitivani termini poseduju neku od navedenih osobina u većoj meri mogu biti označeni sa „,+, ako osobinu poseduju u manjoj meri, onda će biti označeni sa ,-,", i sa „,0" ako su po pitanju određene osobine neutralni (Bugarski, 1996b: 25). Kao rezultat korišćenja navedene matrice zaključuje se da su reči koje bi trebalo standardizovati: kompjuter, štampač, povratna sprega, menadžment i interakcija.

\section{Pristup predložen od strane Filipović i Filipović (1997)}

Filipović i Filipović (1997) ukazuju na nedostatak matrice Bugarskog (1996b), odnosno, ističu da je hijerarhijska organizacija parametara u okviru predložene matrice donekle neprecizna, ističući da su najrelevantniji parametri zapravo internacionalnost, kratkoća i jednoznačnost. Oni ilustruju svoj stav primerima iz oblasti kompjuterske nauke, kontrole kvaliteta i osiguranja kvaliteta, lingvistike i tehnike (Filipović and Filipović, 1996: 2-3). Korišćenjem tri parametra odnosno kriterijuma (internacionalnost, kratkoća i jednoznačnost), Filipović i Filipović su kroz skraćenu verziju navedene matrice, propustili sledeće terminološke alternative iz gore navedenih oblasti (e-mail(i-mejl)/elektronska pošta, cartridge (kartridž)/?, web (veb)/ mreža, home page/matična strana, browser (brauzer)/?, surf/?; odit/provera, sertifikat/potvrda, procedura/postupak; kondukcija/provođenje, ekspanzija/ širenje, aerosol/raspršene tečnosti u gasu), a zatim su naveli akronime koji su strukturalno potpuno adaptirani srpskim morfosintaktičkim pravilima (CD [tse-de], RAM [ram]; RAB [rab], TQM [te-ku-em]; NP [en-pi], VP [vipi], PP [pi-pi], GB [dÛi-bi]; BOF [bof], ASME [asme], MHD [em-ha de] (Filipović and Filipović, 1997: 3-4).

Filipović i Filipović (1997: 4) zaključuju da ovakav lingvistički model nudi skup parametara kojima se može meriti standardizacijski potencijal datih termina i odrediti koja je od predloženih opcija (pozajmljenica ili 
STAVOVI POLJOPRIVREDNIH STRUČNJAKA PREMA ANGLICIZMIMA/PREVODNIM EKVIVALENTIMA U NAUČNOJ TERMINOLOGIJI NA SRPSKOM JEZIKU

prevodni ekvivalent) podesnija da bude prihvaćena ili standardizovana. U njihovom istraživanju, pozajmljenice su svakako prikladnije nego srpske terminološke alternative za navedene oblasti, stoga se predlaže da treba standardizovati internacionalne termine kao prikladnije i na taj način se osloboditi lingvističkog ,purizma” kako bi se načinio korak ka naprednijoj i kompleksnijoj internacionalnoj saradnji (Filipović and Filipović, 1997: 4).

\section{Materijal i metod}

Kao što Bugarski (1996b) i Filipović i Filipović (1997) napominju, predložene matrice se mogu primeniti ne samo na oblasti kojima su se oni bavili, već i na sve oblasti ljudskog delovanja. U nastavku ćemo pokušati da model koju su koristili Filipović i Filipović primenimo na terminološke alternative iz oblasti poljoprivrede uz malo prilagođavanje samog procesa vrednovanja. S obzirom na to da je posredi preliminarno istraživanje, odlučili smo se za ovaj model jer sadrži manji broj kriterijuma u odnosu na model Bugarskog (1996). Takođe, smatramo da su navedeni kriterijumi veoma važni za vrednovanje terminoloških alternativa. U našem slučaju, termine će vrednovati isključivo stručnjaci iz različitih oblasti poljoprivrede. Primeri terminoloških alternativa za ovo preliminarno istraživanje su uzeti iz Zbornika izvoda radova predstavljenih na simpozijumu „Inovacije u ratarskoj i povrtarskoj proizvodnji" u oktobru 2009. godine, a pojedina moguća terminološka rešenja su predložena dodatno korišćenjem rečnika - Veličkov (2001), Kolčar (2002) i Klajn i Šipka (2008), kao i rada koji su napisali Molnar i sar. (1999). Opredelili smo se za oblast poljoprivrede, prvenstveno iz razloga što se o šarolikosti terminoloških alternativa koja postoji u ovoj oblasti malo pisalo (Stojanović, 1996), ali i zbog sve češćeg javljanja terminoloških sinonima u naučnim i stručnim radovima koji stvaraju zabunu i vode ka dvosmislenosti i nepreciznosti (videti: Molnar i sar., 1999; Silaški, 2012).

\section{Instrument}

Za ovo istraživanje je korišćen upitnik koji je poslat stručnjacima iz različitih oblasti poljoprivrede, koji rade bilo na visokoškolskim ustanovama ili u naučnim institutima u Republici Srbiji. U istraživanju 
je učestvovalo ukupno dvadeset i dva ispitanika $(n=22)$, iako je upitnik poslat na znatno veći broj adresa. Upitnik se sastojao iz dva dela. U prvom delu, od ispitanika se tražilo da od ponuđenih terminoloških alternativa (anglicizam/srpski prevodni ekvivalent) izaberu termin koji koriste ili bi upotrebili u svom naučnom radu (grafikon 1). Takođe, omogućeno je da svoj izbor navedenih terminoloških alternativa prokomentarišu, kao i da dodaju još neke moguće terminološke alternative ukoliko smatraju da postoje. U drugom delu upitnika se od ispitanika očekivalo da izaberu između već pomenutih alternativa imajući u vidu tri parametra: internacionalnost, kratkoću i jednoznačnost (grafikon 2).

\section{Rezultati i diskusija}

Kao što se na grafikonu 1 može videti, analizirano je osam parova terminoloških alternativa.

Grafikon 1 pokazuje da su u slučaju pet parova terminoloških alternativa ispitanici prednost dali anglicizmima (biplot/dvoparcela (73\%/27\%), čizel/razrivač (64\%/36\%), koncern/grupa formalno nezavisnih preduzeća $(82 \% / 18 \%)$, malčiranje/zastiranje zemljišta $(55 \% / 45 \%)$, marketing/ plasmana robe(na tržištu) $(82 \% / 18 \%)$ ), dok su se u slučaju dva para terminoloških alternativa, ispitanici odlučili za srpske prevodne ekvivalente no-till/,,bez obrade zemljišta” (45\%/55\%), split-plot/ podeljena parcela $(27 \% / 73 \%))$. Što se tiče para terminoloških alternativa stay-green/,,zelena biljka do berbe”, polovina ispitanika (50\%) je bila za pozajmljenicu, dok je druga polovina (50\%) bila za srpski prevodni ekvivalent. Ono što je zanimljivo jeste da su određene lekseme napisane u izvornom engleskom obliku (biplot, no-till, split-plot i stay-green), koje zapravo predstavljaju primere sirovih anglicizama (Prćić, 2005: 145), ispitanici prepoznali kao neadekvatne, osim termina biplot, koji se može naći i promenjen po padežima u nekim kontekstima, na primer, ,grafički prikaz AMMI biplota", što ukazuje na to da se ovaj termin odomaćio i uklopio u srpski jezik i da se prilagođava pravilima srpskog jezika, iako se radi o očiglednom anglicizmu. 
STAVOVI POLJOPRIVREDNIH STRUČNJAKA PREMA ANGLICIZMIMA/PREVODNIM EKVIVALENTIMA U NAUČNOJ TERMINOLOGIJI NA SRPSKOM JEZIKU

U vezi sa terminološkim parom biplot/dvoparcela, ispitanici su naveli da bi prevod mogao biti i ogled na dve parcele. Kada je posredi terminološki par čizel/razrivač, ispitanici smatraju da bi srpski termin stvorio konfuziju, i da se navedeni anglicizam u stručnoj literaturi uglavnom upotrebljava u spoju čizel plug. Kao jedno od prevodnih rešenja za čizel ispitanici navode i opružasti podrivač. Zanimljivo je da je nekoliko ispitanika u vezi sa parom termina koncern/grupa formalno nezavisnih preduzeća, navelo da neki ljudi uopšte i ne znaju pravo značenje tog termina, ali ga koriste jer je kraće, kao i da se kod nas češće upotrebljava termin holding, ali i da srpski prevodni ekvivalent može glasiti grupa nezavisnih preduzeća. Vezano za terminolški par malčiranje/zastiranje zemljišta, neki od ispitanika su predložili i nastiranje zemljišta. Imajući u vidu par marketing/ plasman robe (na tržištu), ispitanici su kao bolji srpski prevodni ekvivalent naveli prodaja robe, zatim trgovina, mada su dodali i da je anglicizam zbog kratkoće prihvatljiviji. Što se tiče terminoloških alternativa no-till/,,bez obrade zemljišta", ispitanici su napisali da se u naučnim radovima sreću i termini redukovana obrada i direktna setva. Kada je u pitanju par splitplot/podeljena parcela, ispitanici kažu da se split-plot uglavnom koristi u spoju sa ogledom, ili se koristi i srpski prevodni ekvivalent razdeljene parcele dajući primer ,po metodi razdeljenih parcela”. Kada se u obzir uzme terminološki par stay-green/,,zelena biljka do berbe”, ispitanici navode da je srpski ekvivalent jasniji i kao alternativu koja se takođe može upotrebiti predlažu i dugo zelen.

Uzimajući u obzir drugi deo upitnika (grafikon 2) koji je u vezi sa kriterijumima internacionalnost, kratkoća i jednoznačnost, uočavamo malo drugačiju sliku od one koju vidimo na grafikonu 1 .

\section{II}

Grafikon 2 ukazuje na to da bi ispitanici pre upotrebili anglicizme nego srpske prevodne ekvivalente u većini slučajeva kada se u obzir uzmu tri navedena kriterijuma. Kod terminoloških parova biplot/dvoparcela, čizel/razrivač, koncern/grupa formalno nezavisnih preduzeća, malčiranje/ zastiranje zemljišta, marketing/ plasman robe (na tržište), split-plot/podeljena parcela i stay-green/,zelena biljka do berbe”, uočavamo da je većina ispitanika izabrala anglicizme u odnosu na srpske prevodne ekvivalente. 
U slučaju terminološkog para no-till/,,bez obrade zemljišta”, vidimo da se veći broj ispitanika opredelio za srpski prevodni ekvivalent jedino kada se radi o jednoznačnosti, dok se većina ispitanika opredeljuje za anglizicam kada su posredi internacionalnost i kratkoća.

Ono što su neki od ispitanika naveli i sa čime se slažemo jeste da se ograničenje ovog modela ogleda u tome što prva dva navedena kriterijuma daju prednost anglicizmima, ali takođe smatramo da je navedena matrica dobra za početak rada na usklađivanju naučne terminologije, kao i da su navedena dva kriterijuma vrlo bitna. Iz ovoga sledi da bi se matrica, koja bi se možda mogla koristiti za standardizaciju naučne terminologije, trebalo proširiti i uključivati mnogo više parametara, o čemu uostalom govori i Bugarski (1996b, 27) ističući da treba uzeti što više kriterijuma kako bi rezultati bili objektivni. Dakle, ovakav model matrice može poslužiti samo kao jedan od koraka u složenom procesu standardizacije naučne terminologije.

Treba napomenuti da u ovo istraživanje nismo uključili internacionalizme za koje Bugarski (Bugarski, 1991: 135) ističe da „u nauci i tehnici preovlađuju kovanice od grčkih i latinskih tvorbenih elemenata, ali prilagođene izgovoru i pisanju engleskog i iz njega prenete u druge jezike", napominjući da su ovi internacionalizmi po tvorbi greko-latinizmi, a po jeziku nastanka anglicizmi. Neki primeri za takve internacionalizme i njihove srpske prevodne ekvivalente bi bili sledeći: agroekosistem/poljoprivredni ekosistem, biodiverzitet/biološka raznolikost, determinacija/određivanje, dormancija/mirovanje, implementacija/primena, interakcija/međusobno dejstvo, inokulacija/cepljenje, kompetitor/konkurent, revitalizacija/ponovno oživljavanje, heritabilnost/naslednost .

Rezultati navedenog preliminarnog istraživanja u vezi sa terminološkim alternativama iz oblasti poljoprivrede potkrepljuju tvrdnju koju su izneli Filipović i Filipović, da je većina navedenih anglicizama, prema mišljenju ispitanika, pogodnija za upotrebu u poređenju sa njihovim srpskim ekvivalentima, pa stoga, možemo pretpostaviti i za standardizaciju. Takođe, rezultati ovog istraživanja ukazuju i na neophodnost jednog sveobuhvatnijeg istraživanja jer i sami stručnjaci iz oblasti poljoprivrede naglašavaju neadekvatnost srpskih prevodnih ekvivalenata. Ispitanici napominju da ako se strana reč, uglavnom engleskog porekla, prevede jednom rečju na srpski jezik, u mnogim slučajevima se gubi značenje i dobija se termin koji je približnog značenja kao izvorna reč. Ako se prevede opisno kako bi se sačuvalo značenje, reč je preduga, i onda se uglavnom pribe- 
STAVOVI POLJOPRIVREDNIH STRUČNJAKA PREMA ANGLICIZMIMA/PREVODNIM EKVIVALENTIMA U NAUČNOJ TERMINOLOGIJI NA SRPSKOM JEZIKU

gava upotrebi anglicizama. Međutim, stiče se utisak da nebriga stručnjaka iz različitih oblasti, konkretno iz oblasti poljoprivrede, vodi ponekad u prihvatanje anglicizma iz želje da se zvuči naučnije što vodi i do anglosrpskog jezika (Prćić, 2005). Ne treba zanemariti ni mogućnost pogrešnog tumačenja ili nastanak poteškoća i zabune usled korišćenja različitih termina koji se odnose na isti pojam.

Uzimajući u obzir tri značajna kriterijuma (internacionalnost, kratkoću i jednoznačnost) iz navedenog preliminarnog istraživanja se može ukazati na to da su ispitanici prepoznali internacionalnost kao izuzetno značajan kriterijum pri odabiru terminoloških alternativa. Smatramo da ne treba insistirati na jezičkom purizmu i zagovarati potpuno odbacivanje tuđica, jer se uz pomoć njih bogati leksika jednog jezika. Dalje, kratkoća takođe predstavlja bitan faktor, jer se naučnici i stručnjaci uglavnom opredeljuju za kraće lekseme, prigebavajući na taj način ekonomičnosti. Pored toga, jednoznačnost je vrlo bitna u jeziku nauke jer se njome smanjuje nejasnost i zabuna.

\section{Zaključak}

Na kraju, možemo donekle dati odgovor na pitanja o (ne)upotrebi anglicizama u srpskom jeziku. Smatramo da u srpskom jeziku, a posebno u naučnom registru, treba upotrebljavati anglicizme sa merom, tj. onda kada za njih ne postoji prikladna srpska terminološka alternativa i kada bi se prilikom prevoda izgubilo nešto od značenja reči. Dakle, ukoliko ne postoji srpski termin, bolje je prihvatiti anglicizam nego izmišljati reči ili izraze koji ponekad mogu predstavljati prepričan termin. Iz navedenog preliminarnog istraživanja smo donekle sagledali stavove poljoprivrednih stručnjaka o upotrebi anglicizama i srpskih prevodnih ekvivalenata. Iako su u istraživanje bila uključena samo tri kriterijuma, stručnjaci iz oblasti poljoprivrede su se u velikoj meri opredelili za upotrebu anglicizama, ističući uglavnom neadekvatnost prevodnog ekvivalenta. Takođe, u svojim komentarima su istakli da se prilikom prevoda ponekad gubi pravo značenje i da je prevodni ekvivalent neretko znatno duži kao i da je često veoma teško prevesti određene termine.

Da zaključimo: iako se piše o neophodnosti usklađivanja naučne terminologije, kada je reč o o usklađivanju naučne terminologije iz oblasti poljoprivrede, ništa se nije promenilo u poslednjih dvadesetak godina. Smatramo da bi u budućnosti trebalo više pažnje posvetiti problema- 
tici ove vrste kao i da bi uzajamno delovanje i timski rad stručnjaka iz određenih oblasti i lingvista sigurno mogli mnogo da doprinesu rešavanju pitanja standardizacije naučne terminologije u srpskom jeziku uz adekvatnu podršku odgovarajućih državnih institucija.

I Terminološke alternative: anglicizam/srpski prevodni ekvivalent

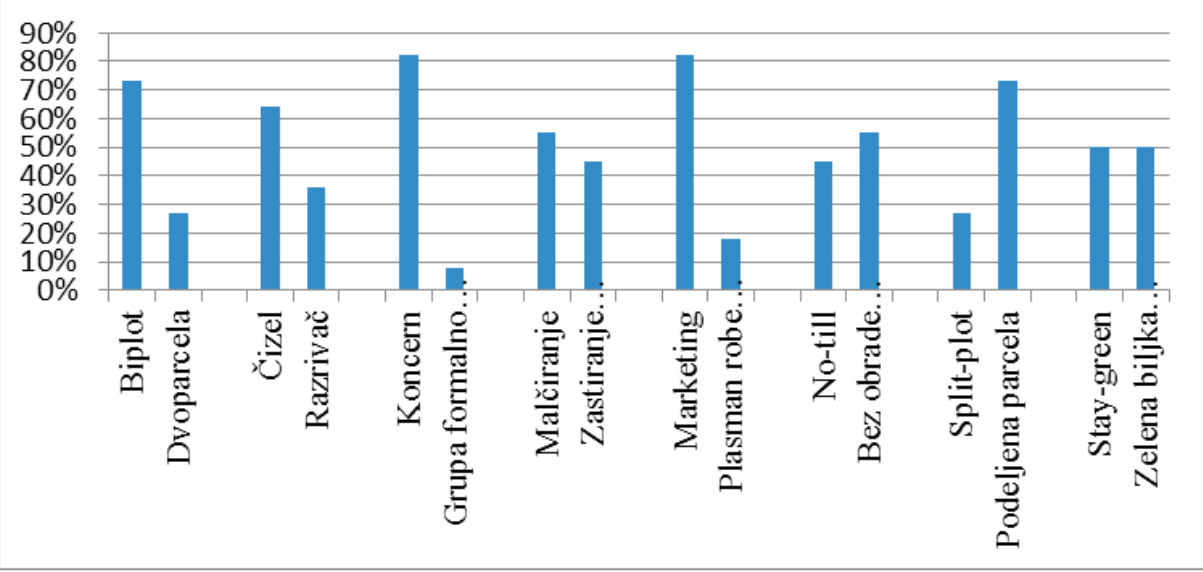

II Terminološke alternative prema tri kriterijuma: internacionalnost, kratkoća i jednoznačnost.

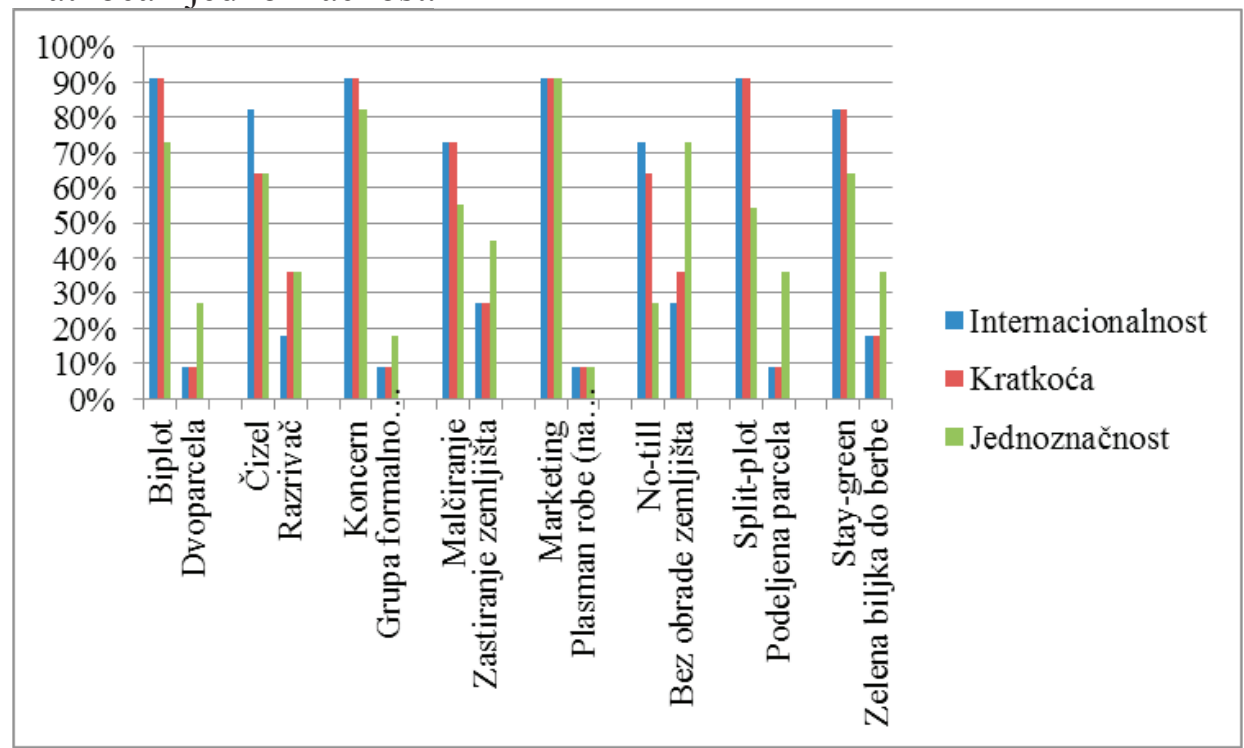


STAVOVI POLJOPRIVREDNIH STRUČNJAKA PREMA ANGLICIZMIMA/PREVODNIM EKVIVALENTIMA U NAUČNOJ TERMINOLOGIJI NA SRPSKOM JEZIKU

\section{Речници}

Клајн, И. и М., Шипка (2008). Велики речник страних речи и израза. (3. допуњено издање). Нови Сад: Прометеј

Kolčar, V. (2002). Englesko-srpski i srpsko-engleski poljoprivredni rečnik. Beograd-Zemun: Institut za kukuruz „Zemun polje”.

Veličkov, Lj. (2001). Poljoprivredni rečnik: englesko-srpski i srpsko-engleski. Beograd: Poslovni sistem „Grmeč”-,Privredni pregled”.

\section{Литература}

Bojković, T. (28. februar 2010 ). POD LUPOM: Kako se spasti od „englezitisa": Sori, po difoltu ne nosim kežual za svaki ivent... Politika. [online]. Dostupno preko: http://www.politika.rs/rubrike/Magazin/Soripo-difoltu-ne-nosim-kezual-za-svaki-ivent.lt.html [15. марта 2010.]

Брборић, Б. (2006а). Однос према туђицама : С мером али без аверзије. У Б. Брборић, Ј. Вуксановић, Р. Гачевић (ур.), Српски језик у нормативном огледалу (пп.391-411). Београд: Београдска књига.

Брборић, Б. (2006б) С језика на језик. Интернет издање. Доступно преко: http://www.rastko.org.yu /filologija/bbrboric-jezik/index.html [10. марта 2010].

Bugarski, R. (1991). Uvod u opštu lingvistiku. Beograd: Zavod za udžbenike i nastavna sredstva.

Bugarski, R. (1996a). Lingvistika u primeni. Beograd: Čigoja/XX vek.

Бугарски, Р. (1996б). О вредновању термина. У Н. Винавер и сар. (ур.). Стандардизација терминологије (пп. 25-27). Београд: САНУ.

Filipović, J. (2009). Moć reči. Beograd: Zadužbina Andrejević.

Filipović, J. and J.Filipović. (1997). General trends in standardization of scientific terminology in Serbian: A critical analysis of the state of affairs. International conference on terminology, pp. 285-291. [on-line]. Dostupno preko http:/www.uzei.com/Modulos/UsuariosFtp/Conexion/archivos18A.pdf [26.februara 2010].

Mićić, S i D. Sinadinović. (2013). Anglicizmi u jeziku medicinske nauke i struke. U N. Silaški i T. Đurović (ur.), Aktuelne teme engleskog jezika nauke i struke u Srbiji (pp.93-105). Beograd: Centar za izdavačku delatnost Ekonomskog fakulteta u Beogradu. 
Milić, M. (2013). Stvaranje, standardizacija i kodifikacija sportske terminologije u srpskom jeziku. U N. Silaški i T. Đurović (ur.), Aktuelne teme engleskog jezika nauke i struke u Srbiji (pp.77-90). Beograd: Centar za izdavačku delatnost Ekonomskog fakulteta u Beogradu.

Molnar, I., M. Đević, D. Marković, M. Martinov, N. Momirović, V. Lazić, N. Škrbić, J. Turan, J. Kurjački (1999). Terminologija i klasifikacija konzervacijske obrade zemljišta. Savremena poljoprivredna tehnika, $25: 4,139-153$

Ostler, N. (2008). Carstva reči. Beograd: Geopoetika

Prćić, T. (2004). O anglicizmima iz četiri različita ali međupovezana ugla. Zbornik Matice srpske za filologiju i lingvistiku, 47/1-2, 113-129.

Préić, T. (2005). Engleski u srpskom. Novi Sad: Zmaj

Préić, T. (2006a). Globalna angloCOOLtura i njen uticaj na sinonimiju srpskog jezika. U Lj. Subotić (ur.), Susret kultura (pp. 529-535). Novi Sad: Filozofski fakultet.

Прћић, Т. (2006б). Српски или англосрпски-питање је сад. У Б. Брборић, J. Вуксановић, Р. Гачевић (ур.), Српски језик у нормативном огледалу (пп. 412-422). Београд: Београдска књига.

Silaški, N. (2012). Srpski jezik u tranziciji: o anglizicmima u ekonomskom registru. Beograd: Centar za izdavačku delatnost Ekonomskog fakulteta u Beogradu.

Стојановић, А. (1996). Покушај уједначавања српске пољопривредне терминологије. У Н. Винавер и сар. (ур.). Стандардизација терминологије (пп.115-118). Београд: САНУ.

Винавер, Н. (1996). О терминологији: између праксе и теорије. У Н. Винавер и сар.(прир.). Стандардизација терминологије (пп.21-24). Београд: САНУ.

\section{Izvor}

Glamočlija, Đ. i S. Oljača. (2009). Inovacije u ratarskoj i povrtarskoj proizvodnji. Zbornik izvoda sa IV Simpozijuma sa međunarodnim učešćem održanog 23. i 24. oktobra 2009. godine. Beograd-Zemun: Poljoprivredni fakultet 
STAVOVI POLJOPRIVREDNIH STRUČNJAKA PREMA ANGLICIZMIMA/PREVODNIM EKVIVALENTIMA U NAUČNOJ TERMINOLOGIJI NA SRPSKOM JEZIKU

Danijela D. Đorđević

\section{Summary \\ ATTITUDES OF AGRICULTURAL EXPERTS TOWARDS ANGLICISMS/TRANSLATION EQUIVALENTS IN SERBIAN SCIENTIFIC TERMINOLOGY}

The increasing use of the English language leads to the need for harmonisation of scientific terminology in the Serbian language. Although scientific areas as well as the language used for academic purposes are considered to be very precise and clear, when it comes to terminology, the situation is far from ideal. As for the anglicisms and their translation equivalents, it appears that experts use the terms that they regard as the most suitable. Thus, we might find the examples of terms, directly taken from the English language without any adjustment to the Serbian language, translated or partially translated into the Serbian language, at the same time, referring to the same concept. In this regard, we have listed some possible ways of evaluating alternatives (anglicism/Serbian translation equivalent) relying on existing models. This paper is aimed at examining the attitudes of agricultural experts towards the use of anglicisms and Serbian translation equivalents in scientific papers. The results indicate the need for more comprehensive research and teamwork of linguists and experts in certain scientific fields as well as relevant state institutions in order to harmonize the existing terms and reduce inconsistency, imprecision and vagueness of the scientific terminology.

Key words: English, Serbian, scientific terminology, agriculture. 